osmoregulatory mechanisms. Undoubtedly the most comprehensive chapter is one by Healey. More than 230 references, published throughout the past century, have been used to compile a full account of the central nervous system. In the discussion by Kleerekoper of the relative importance of the lamprey sensory systems the incomplete explanation of abbreviated labels in several diagrams proved to be distracting.

Unfortunately, a delay in the publication of Volume 2 has inevitably dated the book to an extent. However, the editors are to be congratulated for the wide scope, cohesion and absence of duplication throughout both volumes. This book will become a standard source of reference, yet at the same time should act as a stimulus to research scientists to investigate many of the outstanding questions. One message that comes through most clearly is the call for more work on the predatory and marine phases of the animal's life history. Alan D. Pickering

\section{Phytogeography}

Floristics and Paleofloristics of Asia and Eastern North America. Edited by Alan Graham. (Proceedings of Symposia for the Systematics Section, XI International Botanical Congress, Seattle, Washington, 1969, and the Japan-United States Cooperative Science Program, Corvallis, Oregon, 1969.) Pp. xii +278. (Elsevier: Amsterdam, London and New York, 1972.) Dfl. $75 ; \$ 23.50$.

THIS is a collection of fourteen papers

\title{
Boojum Tree
}

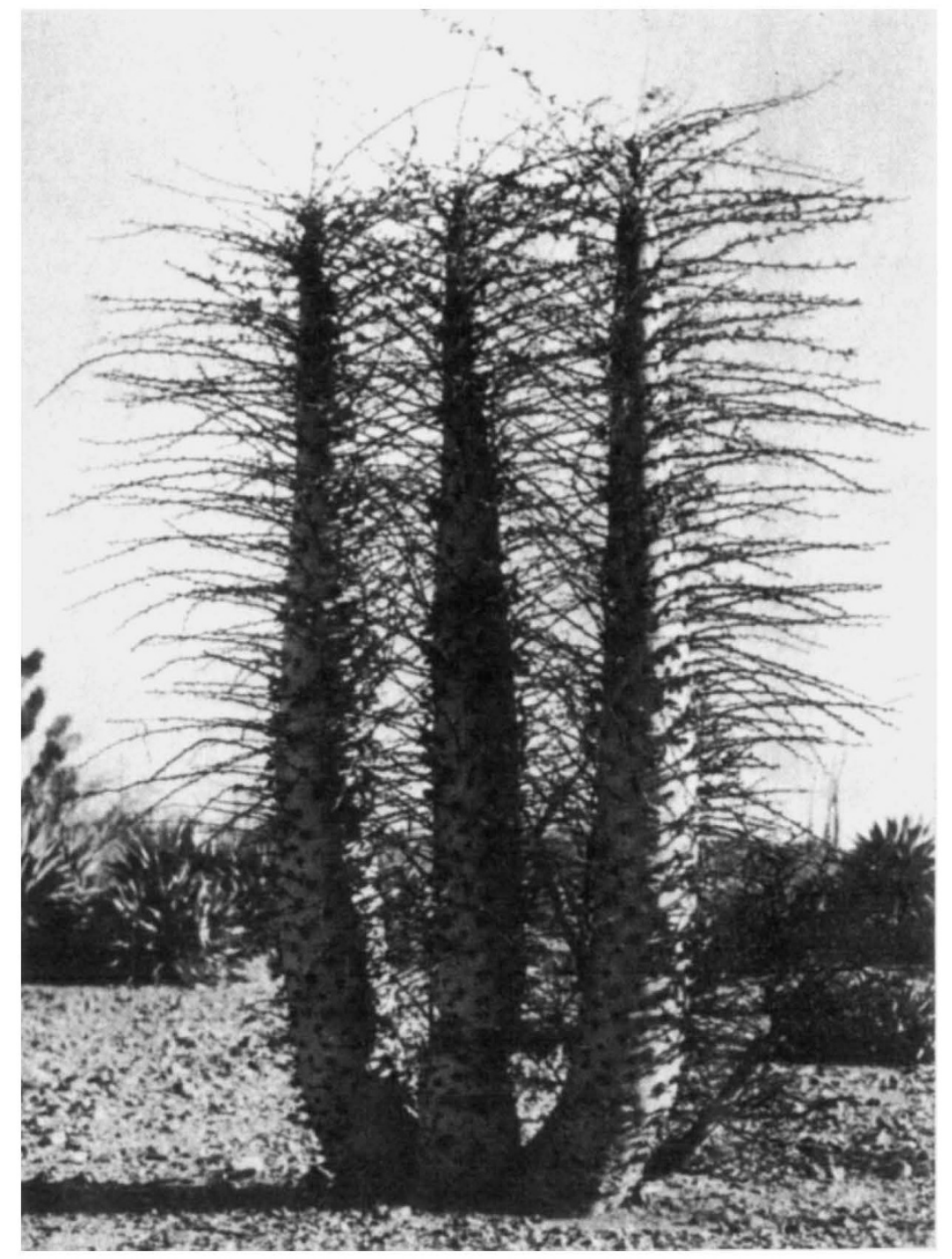

A member of the Fouquieraceae, Idria columnaris, otherwise known as the Boojum tree. The thick stems are adapted to enable the plant to store water and survive in the desert of southeastern California. This is one of the photographs in The Arena of Life, by Lorus and Margery Milne (George Allen and Unwin, London, 1972; f5.25), a lavishly illustrated account of some aspects of plant and animal ecology in various parts of the world. contributed to the two symposia mentioned above, arranged as chapters.

As with many publications of this kind the items included vary considerably both in length and substance and not all of them can claim great originality, but among them are several important contributions to their subjects, and the book is therefore a worthwhile enterprise providing a useful source of information on a number of topics.

To the phanerogamist the most noteworthy chapter is certainly that by Yurtsev on "The Phytogeography of Northeastern Asia and the Problem of Transberingian Floristic Interrelations". This is a long and valuable account of the plant life east of the River Lena and north of 60 degrees $N$, a huge region about which many western botanists have had little opportunity of learning much and of which a great deal is likely to be heard in the future, and it is made all the more useful by a good bibliography includng many references to the work of Russian botanists.

Palaeobotanists are also well served, by three chapters, the longest by Leopold and MacGinitie on Tertiary floras of the Rocky Mountains; by Wolfe, on the interpretation of Alaskan Tertiary floras; and by Tanai, who discusses the Tertiary history of vegetation in Japan.

For the cryptogamists there is a chapter, by Nishida, outlining the distribution of Japanese ferns ; and another, by Kurokawa, concerning the lichens of Japan and North America. A long account of the bryophytes common to Japan and the United States, by Iwatsuki, is somewhat marred by the use of a Mercator-like projection for some of the maps, making one wonder when, at long last, botanists will cease to depict distributions outside the tropical regions in this way.

The remaining chapters are on subjects familiar to those interested in the distribution of the Angiosperms, and, although they should not be neglected, they do not break much fresh ground. The book is well produced and the translations from Russian and Japanese read easily.

R. GOOD

\section{Ant Culture}

Gardening Ants, The Attines. By Neal A. Weber. Pp. xvii + 146. (The American Philosophical Society: Philadelphia, 1972.) \$8.

ANTs of genus Atta are perhaps better known as "leaf-cutting" or "parasol" ants because they carry pieces of leaf cut from a wide variety of plants into their nests. Many Attines are less conspicuous, but all use plant material to cultivate fungi in their nests and, although specific nest fungi are found with some other ants, only the Attines 